Original Research Article

\title{
Prevalence, knowledge, attitude and practice regarding self-medication among medical, dental and paramedical students in a tertiary care hospital
}

\author{
Madhulika Johnson, Dinesh Kumar Badyal*
}

Department of Pharmacology, Christian Medical College and Hospital, Ludhiana. Punjab, India

Received: 13 July 2018 Accepted: 04 August 2018

\section{*Correspondence to:}

Dr. Dinesh Kumar Badyal, Email: dineshbadyal@ gmail.com

Copyright: (C) the author(s), publisher and licensee Medip Academy. This is an openaccess article distributed under the terms of the Creative Commons Attribution NonCommercial License, which permits unrestricted noncommercial use, distribution, and reproduction in any medium, provided the original work is properly cited.

\begin{abstract}
Background: Self-medication is practiced universally. Having medical knowledge plays a vital role in its prevalence. It is more prevalent in higher education course students especially medical students. However, it is increasing in dental and paramedical students. Hence, this study was conducted to evaluate self-medication among medical, dental and para-medical students in a tertiary care hospital.
\end{abstract}

Methods: A cross sectional questionnaire based study was conducted among 449 undergraduate students. They were divided into three groups. A questionnaire was developed based on literature. The questionnaire was validated and finalised. The paper questionnaire was administered to students. The data collected from questionnaires was analysed. The results were expressed as percentages and frequencies.

Results: The male female ratio of students who filled questionnaire was 65:35. All the students $(100 \%)$ reported that they practice self-medication. The most common reason for self-medication was prior experience $(36 \%)$ in group A as well as in group B (46\%), but in group C, $39 \%$ mentioned no serious problem. Main information source was family members in all the groups (A 57\%, B 53\%, C $29 \%$ ) followed by advice from senior/friends. Fever was most common symptom reported $(29 \%)$ by group A followed headache $(28 \%)$ in group C and cough and cold (23\%) in group B. The commonest group of drugs used is cough syrups $(25 \%)$ in group B, followed by analgesics (23\%) in group C and antipyretics $(21 \%)$ in group A.

Conclusions: Self-medication is growing among dental and paramedical students too. It is necessary to educate them about self-medication to prevent future disastrous consequences as well as to make them aware of appropriate use of selfmedication.

Keywords: Dental, Medical, Para-medical students, Self-medication

\section{INTRODUCTION}

Self-medication practice is commonly experienced worldwide. According to World Health Organisation (WHO), self-medication is defined as "use of pharmaceutical or medicinal products by the consumer to treat self-recognized disorders or symptoms, the intermittent or continued use of a medication previously prescribed by a physician for chronic or recurring disease or symptom, or the use of medication recommended by lay sources or health workers not entitled to prescribe medicine". ${ }^{1}$ The prevalence rate of self-medication is quite high. Globally there is wide variation in its prevalence varying from 12-99\% e.g. in Egypt 80.9\%..$^{2,3}$ Recent Indian studies also reported rise in self-medication e.g. $96 \%$ in Bangalore. ${ }^{4,5}$ 
Self-medication has its own benefits and drawbacks ${ }^{1}$. Selfmedication carries advantages only if used as a self-care component. Drawbacks include irrational drug use, increased drug resistance, adverse drug reactions, drug dependence etc. ${ }^{1}$ Educational status, friends, family, society and drug advertisements etc., are influencing factors which affect the pattern of self-medication. ${ }^{6} \mathrm{~A}$ study had described that educated people practiced selfmedication more than illiterates. ${ }^{7}$ Higher education and professional status has been mentioned as predictive factor. ${ }^{8}$ It is equally practiced by doctors as well by medical students. ${ }^{9}$ Several studies had also mentioned that influences of pharmacology subject knowledge on increased prevalence among medical students. ${ }^{5,10}$ Not only medical knowledge of students but availability of drugs as free samples and influences of internet also plays a significant role. ${ }^{11}$

A study conducted among medical and dental students stated that $92.7 \%$ students practiced self-medication. ${ }^{12} \mathrm{~A}$ similar pattern has been seen reported among medical students from government and non-government medical colleges. $^{4}$ According to another study, which was conducted amongst medical students, self-medication is prevalent in about $83 \%$ of first as well as second year students. ${ }^{8}$ In a comparison study, higher practice of selfmedication was observed in dental $(54.1 \%)$ as compared to non-dental students $(42.3 \%){ }^{13,14}$

Another study reported increase in self-medication amongst nursing students $(84.50 \%) .{ }^{15}$ Another comparison study between medical and nursing students had demonstrated that $81 \%$ nursing students practiced selfmedication versus $75.3 \%$ in medical students. ${ }^{16}$ Many studies had been done among medical and non-medical students, but very limited data available about dental and paramedical (nursing, physiotherapist and allied health) students. Hence, this study was designed to evaluate prevalence of self-medication and to study knowledge, attitude and practice toward self-medication among medical, dental and para-medical students in tertiary care centre.

\section{METHODS}

The study was cross-sectional. The study was approved by institutional research committee.

\section{Study population}

A total of 460 students participated in study, out of which 11 were excluded due to incomplete responses. Data from 449 students from different courses such as medical, dental, nursing, physiotherapy and allied health sciences was included in the study. Both male and female students were taken. Written informed consent was duly signed by all participants.

This was a questionnaire based study. The questionnaire was designed based on literature. It was revised after review by peers and pilot testing on small group of students. The final printed questionnaire was given to all participants students. Filling of questionnaire took 10-15 minutes. For ethical concern, the questionnaire was kept anonymous. The purpose of the study was explained to all participants and details of participants were kept confidential.

The questionnaire comprised of five main domains: demographic characteristics, prevalence, knowledge, attitude and practice toward self-medication. The sociodemographic data include their age, gender, residence, studying course and year. Knowledge part comprised of reasons for self-medication, vital information, advantages and disadvantages of self-medication. Attitude component comprised of sources of information, sources of buying and recommendations for self-medication etc. Practice part included student's faith on a particular system of medication, symptoms for taking self-medication and most common medicines taken for self-medication.

\section{Statistical analysis}

Results were expressed as percentage, frequency and mean \pm standard error (SE) of mean. Analysis was done by using SPSS 20 version.

\section{RESULTS}

Demographic profile and rends of using self-medication are depicted in Table 1. Self-medication was more common among female students (57-78\%) as compared to male students $(22-43 \%)$. This was true across all courses. Approximately $3 / 4^{\text {th }}$ of the students $(70-73 \%)$ were in the range of 18-20 years in the three courses. The next common age group was $>20-25$ years $(26-28 \%)$. The courses wise breakup is given in table1. Self-medication was more common among second year students in medical (39\%) and paramedical (62\%) students as compared to first, third and fourth year students. However, the selfmedication was equally practised $(27 \%)$ by first, second and fourth year dental students. Majority of the medical and dental students (87 and 91\%) are living in hostels. However, half of the paramedical students (52\%) are living in their homes. More than half $(62 \%)$ of medical students have permanent residence outside India, while more than half of dental students have permanent residence in urban/outside India (34/35\%). Permanent residence of more than half of paramedical students $(57 \%)$ was mainly in rural area.

Figure 1 shows various reasons for self-medication. The common reasons for self-medication in group A included 'prior experience' (36\%) followed by 'no serious problems' (33\%) and 'as emergency use' (21\%). Similarly, group B has mentioned 'prior experience' (46\%) followed by 'no serious problem' (27\%) and 'as emergency use' (20\%). However, group C reported the common reason as 'no serious problem' (39\%) followed by 'prior experience' (29\%) and 'emergency use' (24\%). 
The least common reason in the students was 'to save money'.

Table 1: Socio-demographic profile of the study population.

\begin{tabular}{|llllll|}
\hline Parameter & & Total & Group A & Group B & Group C \\
\hline Number of participants (n) & Male students & 449 & $150(33.4)$ & $150(33.4)$ & $149(33.2)$ \\
\hline \multirow{2}{*}{ Gender } & Female students & $156(35)$ & $65(43)$ & $33(22)$ & $58(39)$ \\
& $18-20$ & $293(65)$ & $85(57)$ & $117(78)$ & $91(61)$ \\
\hline \multirow{3}{*}{ Age (years) } & $>20-25$ & $323(72)$ & $109(73)$ & $110(73)$ & $104(70)$ \\
& $>25$ & $121(27)$ & $41(27)$ & $39(26)$ & $41(28)$ \\
\hline Year of study & $1^{\text {st }}$ year & $5(0.01)$ & 0 & 1 & 4 \\
\hline & $2^{\text {nd }}$ year & $140(31)$ & $50(33)$ & $40(27)$ & $50(33.3)$ \\
\hline & $3^{\text {rd }}$ year & $190(42)$ & $58(39)$ & $40(27)$ & $92(62)$ \\
\hline & $4^{\text {th }}$ year & $78(17)$ & $42(28)$ & $29(19)$ & $7(0.5)$ \\
\hline Course & MBBS/BDS/Paramedical & $41(0.09)$ & 0 & $41(27)$ & 0 \\
\hline Living status & Hostel & 150 & $150(33.4)$ & $150(33.4)$ & $149(33.2)$ \\
\hline & Home & $353(79)$ & $130(87)$ & $136(91)$ & $71(47)$ \\
\hline Residence & Rural & $96(21)$ & $20(13)$ & $14(0.9)$ & $78(52)$ \\
\hline & Urban & $50(0.11)$ & $11(22)$ & $11(22)$ & $28(56)$ \\
\hline
\end{tabular}

Values represent number (percentage)

Table 2: Knowledge about vital information and awareness of self-medication.

\begin{tabular}{|c|c|c|c|c|c|c|}
\hline & \multicolumn{2}{|l|}{ Group A } & \multicolumn{2}{|l|}{ Group B } & \multicolumn{2}{|l|}{ Group C } \\
\hline Vital information & Yes & No & Yes & No & Yes & No \\
\hline Common side effects of drug & $117(78)$ & $33(22)$ & $117(78)$ & $33(22)$ & $118(79.2)$ & $31(20.8)$ \\
\hline Precaution of the drugs & $87(58)$ & $63(42)$ & $96(64)$ & $54(36)$ & $116(77.8)$ & $33(22.2)$ \\
\hline Risk related with increase in dose of drug & $100(66.6)$ & $50(33.3)$ & $105(70)$ & $45(30)$ & $99(66.4)$ & $50(33.5)$ \\
\hline Contraindication & $50(33.3)$ & $100(66.6)$ & $45(30)$ & $105(70)$ & $93(62.4)$ & $56(37.6)$ \\
\hline Drug-drug/drug-food interaction & $52(35)$ & $98(65)$ & $36(24)$ & $114(76)$ & $49(32.8)$ & $100(67.1)$ \\
\hline \multicolumn{7}{|l|}{ Awareness } \\
\hline Over the counter medicine & $100(66.6)$ & $50(33.3)$ & $74(49.3)$ & $76(50.6)$ & $91(61)$ & $58(38.9)$ \\
\hline Package insert & $105(70)$ & $45(30)$ & $106(70.6)$ & $44(29.3)$ & $104(69.7)$ & $45(30.2)$ \\
\hline Generic and brand name of medicine & $111(74)$ & $39(26)$ & $112(74.6)$ & $38(25.3)$ & $117(78.5)$ & $32(21.4)$ \\
\hline Completion of treatment & $97(64.6)$ & $53(35.3)$ & $93(62)$ & $57(38)$ & $84(56.3)$ & $65(43.6)$ \\
\hline
\end{tabular}

Values represent number (percentage)

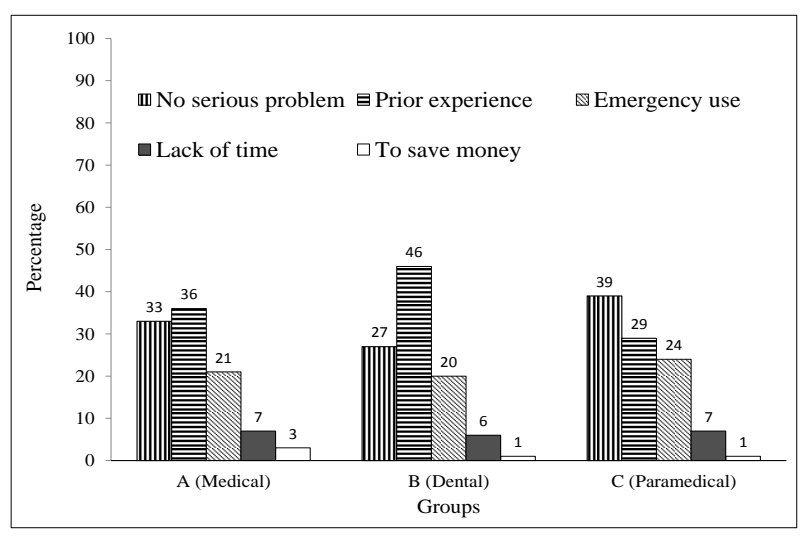

Figure 1: Common reasons for self-medication among students.
Most common symptom for self-medication was 'fever' (29\%) followed by (20\%) 'cough and cold' and 'headache' $(17 \%)$ in group $\mathrm{A}$ as depicted in Figure 2. In group B, 'cough and cold' (23\%) was the most common symptom followed by 'fever' (20\%) and 'headache' (17\%). However, in group $\mathrm{C}$, 'headache' was the most common symptom (28\%) followed by 'fever' $(21 \%)$ and 'cough and cold' $(18 \%)$.

'Antipyretic' was most frequently used medicine used for self-medication in group A $(21 \%)$ followed by 'cough syrup' (19\%) and 'analgesics' (17\%) as shown in Figure 3. Group B reported 'cough syrup' (25\%) as most commonly used followed by 'antipyretics' (18\%) and analgesics $(16 \%)$. Comparatively, group C had mentioned 
analgesics (23\%) most commonly used drug group followed by antipyretics (22\%) and cough syrup (21\%).

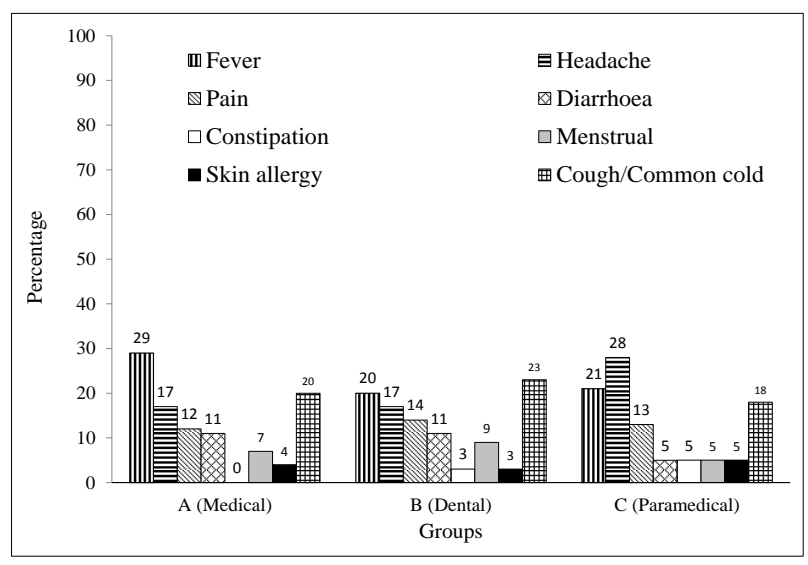

Figure 2: Common symptoms for indulging in self-medication.

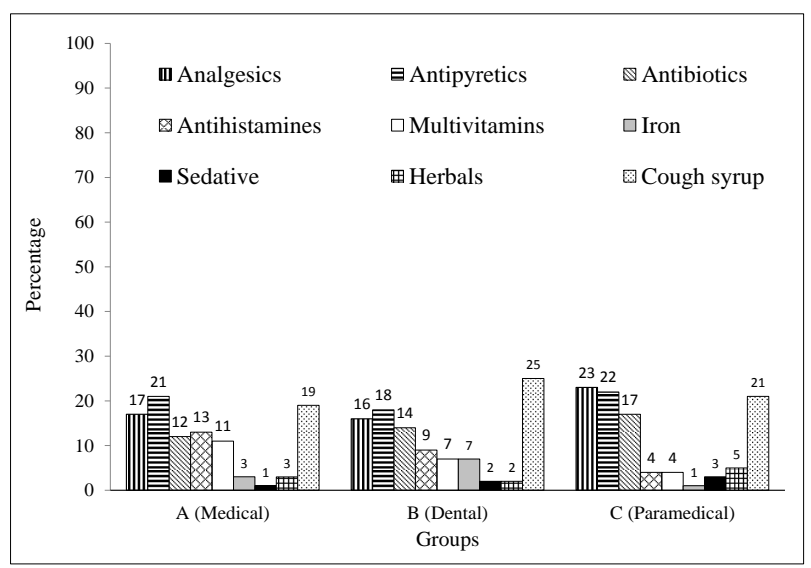

Figure 3: Common group of drugs used for self-medication.

The student's known knowledge about important information of self-medication is shown in Table 2. The important information known in group $\mathrm{A}$ includes 'common side effects' (78\%) followed by 'risk related with increase in dose' $(66.6 \%)$. Likewise, in group B it includes 'common side effects' $(78 \%)$ followed by 'risk related with increase in dose' (70\%). In group C, 'common side effect' (79.2\%) was the known important information followed by 'precaution of drug' $(77.8 \%)$. The important information less known in group A was 'contraindications' (66.6\%) followed by 'drug interactions' (65\%). In group $\mathrm{B}$, students were less known about 'drug interactions' (76\%) followed by 'contraindications' $(70 \%)$. In the same way, in group C, 'drug interactions' (67\%) was important information less known by students followed by 'contraindications' (37.6\%).

The student's known knowledge about awareness of selfmedication is depicted in Table 2. In group A, students were aware about 'generic and brand name of medicines' (74\%) followed by 'package insert' $(70 \%)$. In the same way, group B and C was aware about 'generic and brand name of medicines' (74.6\% and $78.5 \%$ ) followed by 'package insert' (70.6\% and $69.7 \%)$. The students were less aware in group A about 'completion of treatment' $(35.3 \%)$ followed by 'over the counter medicines' $(33.3 \%)$. In group B, students were less aware about 'over the counter medicines' (50.6\%) followed by 'completion of treatment' $(38 \%)$.

The student's known knowledge about benefits and drawbacks of self-medication is illustrated in Table 3. The benefits known by students in group A included 'useful for mild illness' (49\%) benefits followed by 'time saving' (25\%) and 'easy availability' (25\%). Likewise, in group B, benefits were 'useful for mild illnesses' (71\%) followed by 'time saving' (16.6\%). In group $\mathrm{C}$ the benefits mentioned were 'useful for mild illness' (38\%) followed by 'easy availability' (25\%). The drawbacks known by students in group A included 'lack of knowledge about drug dose and frequency' (32\%) followed by 'wrong medication' (21\%) and 'masking of underlying disease' (21\%). Similarly, in group B, known drawbacks included 'lack of knowledge about drug dose and frequency' (36\%) followed by 'masking of underlying disease' (20\%). But in group C, reported drawbacks were 'adverse drug effects' (36\%) followed by 'lack of knowledge about drug dose and frequency’ $(23 \%)$.

Table 3: Knowledge about benefits and drawbacks of self-medication.

\begin{tabular}{|llll|}
\hline & $\begin{array}{l}\text { Group } \\
\text { Benefits }\end{array}$ & $\begin{array}{l}\text { Group } \\
\text { B }\end{array}$ & $\begin{array}{l}\text { Group } \\
\text { C }\end{array}$ \\
\hline Time saving & $37(25)$ & $25(16.6)$ & $30(20)$ \\
\hline Easy availability & $37(25)$ & $17(11)$ & $37(25)$ \\
\hline Money saving & 0 & $2(1)$ & $15(10)$ \\
\hline $\begin{array}{l}\text { Useful for mild } \\
\text { illness }\end{array}$ & $74(49)$ & $106(71)$ & $57(38)$ \\
\hline $\begin{array}{l}\text { Feeling of self } \\
\text { confidence }\end{array}$ & $2(1)$ & 0 & $11(7)$ \\
\hline Drawbacks & & & \\
\hline Adverse drug effects & $23(15)$ & $21(14)$ & $54(36)$ \\
\hline $\begin{array}{l}\text { Lack of knowledge } \\
\text { about drug dose, } \\
\text { frequency }\end{array}$ & $48(32)$ & $54(36)$ & $34(23)$ \\
\hline Wrong medication & $31(21)$ & $23(15.3)$ & $24(16)$ \\
\hline $\begin{array}{l}\text { Masking of } \\
\text { underlying disease }\end{array}$ & $31(21)$ & $30(20)$ & $17(11)$ \\
\hline Disease aggravation & $5(3)$ & $5(3)$ & $5(3)$ \\
\hline Disease interactions & $12(8)$ & $17(11.3)$ & $15(11)$ \\
\hline
\end{tabular}

Values represent number (percentage)

\section{Attitude}

The most common source of information and common source of buying medicine were demonstrated in Table 4. The 'family members' were the common source of information in group A (57\%), group B (53\%) and in group 
C (29\%). Next common source was 'seniors/friends' in all groups A and group B and pharmacist reported by group C. Most common source of buying medicines was 'medical store' in all. 'Left over medicine' was second common source in group A and B group but in group $\mathrm{C}$ 'hospital source' was the second common source. Most of respondents disagree to 'recommendation to use selfmedication'. 'Allopathic' was most trusted system reported by all the groups. 'Ayurvedic' was next trusted system cited by group A (15\%) followed by C group (12\%) then $(11 \%)$ in group B. Few had trust in homeopathic system but some didn't comment.

Table 4: Attitude towards self-medication.

\begin{tabular}{|llll|}
\hline \multicolumn{5}{|l}{ Group A } & Group B & Group C \\
\hline Source of information & & & \\
\hline $\begin{array}{l}\text { Advice from } \\
\text { Senior/friends }\end{array}$ & $41(27.3)$ & $29(19.3)$ & $33(22.1)$ \\
\hline Advice from nurse & $9(6)$ & $9(6)$ & $23(15.4)$ \\
\hline $\begin{array}{l}\text { Advice from } \\
\text { Pharmacist }\end{array}$ & $8(5)$ & $23(15.3)$ & $39(26.1)$ \\
\hline $\begin{array}{l}\text { Advice from } \\
\text { family member }\end{array}$ & $86(57.3)$ & $80(53.3)$ & $43(29)$ \\
\hline $\begin{array}{l}\text { Textbooks/Package } \\
\text { insert }\end{array}$ & $3(2)$ & $7(5)$ & $11(7)$ \\
\hline Media/ Internet & $3(2)$ & $2(1)$ & 0 \\
\hline Source of buying medicine & & \\
\hline Left over medicine & $18(12)$ & $23(15.3)$ & $12(8)$ \\
\hline $\begin{array}{l}\text { Sample given by } \\
\text { physician/pharmaci } \\
\text { st }\end{array}$ & $12(8)$ & $12(8)$ & $6(4)$ \\
\hline Hospital & $8(5)$ & $20(13.3)$ & $27(18)$ \\
\hline Private clinic & $6(4)$ & $6(4)$ & $20(13.4)$ \\
\hline Medical store & $106(71)$ & $89(59.3)$ & $84(56.3)$ \\
\hline Recommendation to use self-medication & \\
\hline Agree & $38(25.3)$ & $48(32)$ & $35(23)$ \\
\hline Disagree & $66(44)$ & $65(43.3)$ & $65(44)$ \\
\hline No comment & $46(30.6)$ & $37(24.6)$ & $49(33)$ \\
\hline Trust in medicine system & & \\
\hline Allopathic & $104(69.3)$ & $\begin{array}{l}103 \\
(68.6)\end{array}$ & $94(63)$ \\
\hline Ayurvedic & $22(14.6)$ & $17(11.3)$ & $18(12)$ \\
\hline Homeopathic & $10(6.6)$ & $18(12)$ & $23(15.4)$ \\
\hline No comments & $14(9)$ & $12(8)$ & $14(9.3)$ \\
\hline Vars ren
\end{tabular}

Values represent number (percentage)

\section{Practice}

Table 5 has mentioned the various practices of selfmedication. Mostly group A (49\%) students were using combined drugs followed by group B (35\%) then $\mathrm{C}$ group (32\%). Group B (43\%) followed by C group (42\%) then A group (35\%) didn't know correct dosage. Group B (56\%) and group C (55\%) followed by (45\%) in group A didn't know correct duration. 'Frequency of administration of self-medication' was occasionally as reported in group B (74\%), group C (72\%) and group A (67\%).
Table 5: Practice towards self-medication.

\begin{tabular}{|c|c|c|c|}
\hline & Group A & Group B & Group C \\
\hline \multicolumn{4}{|c|}{ Any existing medical illness } \\
\hline Yes & $18(12)$ & $23(15)$ & $5(3)$ \\
\hline No & $132(88)$ & $127(85)$ & $144(97)$ \\
\hline \multicolumn{4}{|c|}{ Did you ever combine 2 or more medicine together } \\
\hline Yes & $73(49)$ & $53(35)$ & $47(32)$ \\
\hline No & $77(51)$ & $97(65)$ & $102(68)$ \\
\hline \multicolumn{4}{|c|}{ Did you often know correct dose of a drug } \\
\hline Yes & $97(65)$ & $84(57)$ & $86(58)$ \\
\hline No & $53(35)$ & $66(43)$ & $63(42)$ \\
\hline \multicolumn{4}{|c|}{$\begin{array}{l}\text { Did you often know correct duration of course of that } \\
\text { drug }\end{array}$} \\
\hline Yes & $83(55)$ & $66(44)$ & $67(45)$ \\
\hline No & $67(45)$ & $84(56)$ & $82(55)$ \\
\hline \multicolumn{4}{|c|}{ Frequency of self-medication } \\
\hline Occasional & $101(67)$ & $111(74)$ & $107(72)$ \\
\hline Moderate & $29(19)$ & $18(12)$ & $14(9.3)$ \\
\hline Frequent & $20(14)$ & 21(14) & $28(18.7)$ \\
\hline
\end{tabular}

Values represent number (percentage)

\section{DISCUSSION}

Self-medication is increasing universally and now a very common public problem. In this current study, authors have found $100 \%$ prevalence which was higher as compared to earlier studies., ${ }^{4,5}$ This indicates that selfmedication is increasing among undergraduates day by day. Female students were more involved than male students as reported earlier too. ${ }^{10,17}$ This could be female students wants to maintain their privacy or by nature they tolerate till her problem becomes serious.

As previously described there are many influencing factors such as education, family, friends, advertisement etc., which affect pattern of self-medication. Education plays a significant role in its prevalence. ${ }^{6}$ This study has found more occurrence of self-medication in second year students which was around $40 \%$. This may be because of studying pharmacology subject in second year which was supported by other studies. ${ }^{11,13}$ They are getting all information about drugs like their mechanism, uses, adverse drug reactions etc. In addition they are working up cases in the clinical subjects. All these factors may increase their knowledge as well their confidence level in Pharmacology. ${ }^{18}$ This might encourage them to indulge in self-medication.

In present study, we have found that prior experience was the common reason for self-medication in medical as well in dental students. These finding were similar to earlier findings. ${ }^{7,13}$ With best of author's knowledge, no Indian data is available for allied health and physiotherapy students. But few studies have been done on nursing students. In paramedical group, 'no serious problem' was common reason detected in this group. This outcome is similar to previous studies. ${ }^{16,19}$ 
The most common symptoms observed in this study were fever followed by cough/common cold and headache medical students. Similar results were noticed in previous studies. ${ }^{7,11}$ Dental students have reported cough/ common cold as the most common symptom followed fever. This outcome was similarly noticed in former study. ${ }^{13}$ Headache was the common symptom mentioned in paramedical group followed by fever. These findings were very similar to a study conducted in Ethiopia. ${ }^{20}$

In this present study, the most common drugs used by medical students were antipyretics followed by cough syrups and analgesics. Similar findings were reported by a previous study.${ }^{17}$ However, in dental students cough syrups were commonly used followed by antipyretics and analgesic. These finding are contradictory to findings in prior studies which had mentioned antibiotics and analgesics as common drugs. ${ }^{13,14}$ Paramedical group used analgesics followed by antipyretics and cough syrups. An earlier study mentioned use of a combination of antipyretic, analgesic and cough suppressant as commonly used drug in nursing studnets. ${ }^{15}$

All students trusted allopathic system the most as observed in this study. This is in agreement with earlier studies. ${ }^{5,11,17}$ Students knew about the important information of selfmedication like common adverse effects etc. in this study. This result was similar to previous findings. ${ }^{19}$ Family members were common source of information in all groups. This is contradictory to another study which has mentioned the 'old prescription' as common source of drug infomration. ${ }^{11}$ The reason might be that parents of most of the students are in medical/paramedical profession.

Common source of buying medicine was medical store followed by left over medicine, alike in medical and dental but in paramedical students, medical store was common source followed by hospital. This brings to attention the role of pharmacists. Most of the students were disagreed to 'recommendation to use self-medication'. This finding was contradictory to a former study. ${ }^{8}$ This showed us that students still not clear about benefits or drawback of selfmedication.

As far as concerned about correct dosage and duration of drug, mostly dental and paramedical students did not know correct dosage and duration as compared to medical students. 'Frequency of administration of self-medication' was occasional in this study. This finding is similar to a prior study. ${ }^{8}$ In spite of occasional administration, inappropriate knowledge about drug dosage and duration can leads to risky emergence of drug resistance etc.

\section{CONCLUSION}

This study has concluded that self-medication has high prevalence and is growing among dental and paramedical students. Study has thrown a light on seriousness of this problem. As we know that these students will become doctors, dentist, nurses, assistant physicians and physiotherapists in future, their habit of self-medication can affect them as well as society. Affective measures should be taken to educate them about advantages and disadvantages of self-medication. Learning pharmacology makes them confident only theoretically. Lack of knowing dosage and duration about drug etc. could leads to serious consequences. This emphasis us that all medical sciences undergraduates needs to get educate more about selfmedication.

\section{ACKNOWLEDGEMENTS}

Authors would like to thank all the respondents and to all staff of Pharmacology Department for their full cooperation.

\section{Funding: No funding sources \\ Conflict of interest: None declared \\ Ethical approval: The study was approved by the Institutional Ethics Committee}

\section{REFERENCES}

1. World Health Organization (WHO): Guidelines for the regulatory assessment of medicinal products for use in self-medication. 2000 Available at: http://apps.who.int/medicinedocs/en/d/Js2218e/ (Assessed on 02 March 2018).

2. Lukovic JA, Miletic V, Pekmezovic T, Trajikovic G, Rat-kovic N, Aleksic D. Self-medication practices and risk factors for self-medication among medical students in Belgrade, Serbia. PloS One. 2014;9:1-14.

3. El Ezz NF, Ez-Elarab HS. Knowledge, attitude and practice of medical students towards self-medication at Ain Shams University, Egypt. J Prev Med Hyg. 2011;52:196-200.

4. Tushar MH, Karim MT, Omer, Pavel OF. Assessing the knowledge on self-medication among medical students of Bangladesh. World J Pharma Res. 2017;16:27-33.

5. Manasa CR, Kalpana L, Veena RM, Bharath Kumar VD. Influence of pharmacology on knowledge, attitude and practice of self-medication in 2nd year medical students: observational questionnaire based study. Int J Pharmacol Res. 2017;7:160-4.

6. Ahmadi SM, Jamshidi K, Sadeghi K, Abdi A, Vahid MP. The prevalence and affecting factors on selfmedication among students of Kermanshah University of medical science in 2014. J Clin Diagn Res. 2016;10:IC01-IC04.

7. Pal J, Ahmad S, Pal P, Chatterjee D. Prevalence and pattern of self-medication among undergraduate students in a medical college of Kolkata. Int $\mathbf{J}$ Community Med Public Health. 2017;4:3619-24.

8. Chauhan R. A study of the prevalence, pattern, and perception of self-medication among medical students in North India. Int $\mathrm{J}$ Contemporary Med Res. 2017;4:1970-3. 
9. Montogomery AL, Bradley C, Rochfort A, Panagopoulou E. A review of self-medication in physicians and medical students. Occup Med. 2011;61:490-7.

10. Sankdia RK, Agrawal M, Rekha PB, Kothari N. A questionnaire based study regarding the knowledge, attitude and practice of self-medication among second year undergraduate medical students. Int J Pharmacol and Clin Sci. 2017;6:01-5.

11. Bagewadi HG, Deodurg PM, Patil BV, Zahid SH. Perceptions and practices of self-medication among undergraduate medical students at Gulbarga Institute of Medical Sciences, Kalaburagi, India. Int J Basic Clin Pharmacol. 2018;7:63-7.

12. Gupta S, Singh M. Self-medication among North Indian first-year undergraduate healthcare students: A questionnaire-based study. Trop J Med Res. 2016;19:162-7.

13. Venkataraman G, Gangadharappa SK, Jacob J, Bhaskar N, Kulkarni SB, Gupta A. Assessment of selfmedication practice among students of a dental college of Bangalore city: A cross-sectional study. J Indian Assoc Public Health Dent. 2017;15:73-7.

14. Sanghavi K, Kasabwala K, Gundavda J, Thakur B, Gupta P. Self-medication patterns and practices among undergraduate dental students compared to undergraduate non-dental students- A cross-sectional study. Asian J Med Health. 2017;4:1-9.

15. Ali SS, Sharma S, Ahmed T, Sharma R, Jaiswal M, Chaurasia R. Evaluation of self-medication amongst nursing students of Bastar Region: A questionnaire based study. Int J Pharmacol Res. 2015;5:145-9.

16. Sama S, Mahesh V, Muninarayana C, Anil NS. Study of self-medication patterns among medical and nursing students in deemed medical university. Int $\mathbf{J}$ Basic App Med Sci. 2015;5:280-4.

17. Bhatia MK, Ripudaman S, Akashdeep S, Bhardwaj B.L. Knowledge, attitude and practice of selfmedication among undergraduate medical students of Punjab. J Med Res. 2017;3:151-4.

18. Shankar PR, Dubey AK, Dwivedi NR, Nandy A, Barton B. Knowledge, perception and practice of selfmedication among premedical and basic science undergraduate medical students. Asian J Med Sci. 2016;7;63-8.

19. Patchva LD, Sowmya, Priyambada S, Jagadeesh, Dwaraka. Practice of self-medication among 2nd year medical and dental students. Int $\mathrm{J}$ Basic Clin Pharmacol. 2016;5:2013-6.

20. Abay SM, Amelo W. Assessment of self-medication practices among medical, pharmacy, and health science students in Gondar university, Ethiopia. J Young Pharm. 2010;2:306-10.

Cite this article as: Johnson M, Badyal DK. Prevalence, knowledge, attitude and practice regarding self-medication among medical, dental and paramedical students in a tertiary care hospital. Int $\mathbf{J}$ Basic Clin Pharmacol 2018;7:1822-8. 